\title{
ARTICLE
}

Nutrition during the early life cycle

\section{Improvement in appetite among stunted children receiving nutritional intervention in Bangladesh: results from a community- based study}

\author{
Nurun Nahar Naila $\mathbb{D}^{1} \cdot$ Mustafa Mahfuz $^{1} \cdot$ Muttaquina Hossain $^{1} \cdot$ Michael Arndt $^{2} \cdot$ Judd L. Walson $^{3,4}$. \\ Baitun Nahar ${ }^{1} \cdot$ Tahmeed Ahmed $^{1,3,5}$
}

Received: 19 May 2020 / Revised: 15 November 2020 / Accepted: 9 December 2020 / Published online: 27 May 2021

(c) The Author(s) 2021. This article is published with open access

\begin{abstract}
Background/objectives Stunted children often have poor appetite, which may limit their response to nutritional interventions. We investigated the effect of a nutritional intervention on the appetite status of stunted children.

Methods A longitudinal prospective intervention study was conducted with 50 stunted (length for age; LAZ $<-2)$ (age and sex matched) aged 12-18 months and their mothers in Bauniabadh slum of Dhaka city. The stunted children received the following intervention package: one boiled egg and $150 \mathrm{ml}$ milk daily 6 days a week for 3 months; psychosocial stimulation including structured play activities and parental counseling for 6 months; routine clinical care. Appetite status was measured using an interview-based tool "Early Childhood Appetite and Satiety Tool."

Results Over the period of nutritional intervention, the mean appetite score increased from 49 to 60 in the stunted children and was associated with increased food consumption. Over the intervention period, both egg and milk consumption increased (40.3-49.6 $\mathrm{g}$ and $83.8-138.5 \mathrm{ml}$, respectively).

Conclusions Assessment of appetite status using EACST appears to be a useful tool for monitoring a nutritional intervention in stunted children. This tool may be useful for programs in managing child stunting in low-income countries and an important way to assess the efficacy of a nutritional intervention in these children.
\end{abstract}

\section{Introduction}

Stunting (length-for-age $z$-score, LAZ $<-2 \mathrm{SD}$ ) in children represents chronic undernutrition and is associated with

Supplementary information The online version of this article (https:// doi.org/10.1038/s41430-020-00843-9) contains supplementary material, which is available to authorized users.

Nurun Nahar Naila

nurun.nahar@icddrb.org

1 Nutrition and Clinical Services Division (NCSD), International Centre for Diarrhoeal Disease Research, Bangladesh (icddr, b), Dhaka, Bangladesh

2 PATH, Seattle, WA, USA

3 Department of Global Health, University of Washington, Seattle, WA, USA

4 Childhood Acute Illness and Nutrition Network, Nairobi, Kenya

5 James P. Grant School of Public Health, BRAC University, Mohakhali, Dhaka 1212, Bangladesh poor health outcomes, decreased learning capacity, and diminished productivity [1-3]. Stunting is now more prevalent than other forms of undernutrition, such as wasting and underweight, affecting an estimated 154.8 million children aged $<5$ years in developing countries [4, 5]. Many of the effects of stunting appear to be nearly irreversible after 3-4 years of age [6].

The majority of the world's stunted children reside in Africa and Asia, where 87 and $59 \%$ of the children under 5 years are stunted, respectively [4]. In Bangladesh, an estimated $31 \%$ of under 5 children are stunted and $9 \%$ are severely stunted (HAZ/LAZ <-3SD) [7]. The causes of stunting are multi-sectoral and multifactorial. Major determinants include intrauterine growth restriction, low birth weight, low maternal height, food insecurity, and inappropriate infant and young child feeding practices. Recurrent infections, micronutrient deficiencies, environmental enteric dysfunction, nonresponsive feeding practices, inadequate child stimulation at home [8], and lack of appetite [9] also have a role in occurrence of stunting $[10,11]$. Linear growth faltering may be potentiated directly 
by these factors or through the mediation of decreased appetite [12]. It is evident that current interventions to reverse growth failure and improve health and cognitive outcomes are minimally effective in stunted children.

Nutritional interventions do play an important role in reversing stunting [2, 13]. Unfortunately, single interventions like food or micronutrient supplementation do not appear to effectively normalize growth and reduce morbidity in stunted children $[9,14,15]$. However, data suggest that existing nutritional interventions can reduce stunting prevalence by $\sim 20 \%$ in children under 2 years of age and with all known effective interventions, approximately a third of all stunting could be averted. However, in order to achieve this impact, coverage of feeding interventions, including appropriate complementary feeding and other nutritional approaches, would need to reach $\sim 99 \%$ [6]. One key factor which limits the impact of nutrition interventions may be the inability of stunted children to increase their dietary intake to meet increased metabolic demands [9, 14-18]. Lack of appetite may be a significant barrier to effective nutritional rehabilitation in these children.

Previous longitudinal studies in developed countries have demonstrated considerable improvement in nutritional status through community-based management, such as food and micronutrient supplementations, medical care and growth monitoring [19-21]. In addition to improvements in weight and length/height gain, these studies have also reported decreases in mortality [22-24]. In addition to nutritional interventions, psychosocial stimulation (PS) also has been shown to substantially contribute to the improvement of nutritional status in malnourished children $[25,26]$, although most of these studies have included only moderate and severely wasted hospitalized children $[16,26,27]$.

The majority of studies evaluating nutritional interventions in malnourished children have assessed children's appetite based on the amount of food they consume $[12,17,18]$ rather than using a robust and dedicated measure of appetite status. Such measures are difficult to collect and often rely on caregiver report, which is subject to a number of sources of bias. Therefore, measuring appetite status in children [28] may be a useful tool to monitor the effectiveness of nutrition intervention. Accurate appetite measurements may improve the ability of programs to effectively manage and treat malnutrition in low-income countries, particularly stunting. Recently, we developed and validated a new tool to measure appetite status of under-five children in Bangladesh [28]. The aim of the present study is to determine whether appetite status improves in stunted children who receive a combined intervention (food supplementation (FS) and PS) and living in a slum of Dhaka city.

\section{Methods}

\section{Study design}

This is a community-based longitudinal prospective study.

\section{Sample size calculation}

The sample size was calculated based on FGF-21 using estimates from a previous study [29]. In that study FGF-21 was found correlated positively with percent trunk fat $(r=$ $0.25, P=0.001)$ and bone mineral density $(r=0.30, P<$ $0.0001)$. We assumed that the correlation between FGF-21 level and nutrition intervention in stunted children (group 1) would differ by 0.6 from non-stunted children (group 2).

On the basis of the information, the sample size is 36 children per group assuming $80 \%$ power with level of significance, $\alpha=0.05$.

Sample size $N=36$

Attrition rate $30 \%=36 \times 0.3=10.8$ (11 rounded $)$

Total sample size per group $=36+11=47$ rounded)

Therefore, the total sample size for was 100 children of age 12-18 months.

\section{Study site and participants}

In group 1 (stunted/intervention children), 50 stunted (LAZ <-2) children aged 12-18 months and their mothers, living in Bauniabad slum of Mirpur, Dhaka city, were enrolled after getting written informed consent from their caregivers. Children with severe acute malnutrition (weight-for-length $z$-score $<-3$ with or without edema), chronic illnesses, congenital anomalies, or developmental delay were excluded.

In group 2 (non-stunted/control children), 50 non-stunted $(\mathrm{LAZ} \geq-2)$ children and their caregivers were also enrolled to examine if changes in appetite status and stunting occur among healthy children living in similar environment (Fig. 1).

\section{Early Childhood Appetite and Satiety Tool (ECAST)}

ECAST was administered on mothers/caregivers of the study participants monthly for 6 months. Based on previous literature review and findings from focus group discussions, a 27-item interview-based tool ECAST was developed in Bangladesh. Fourteen FGDs were carried out in rural and urban settings for the development of the tool. The hypotheses for development of tool resulted from the themes and coding of FGDs and appetite assessment tools used in western settings [28]. 


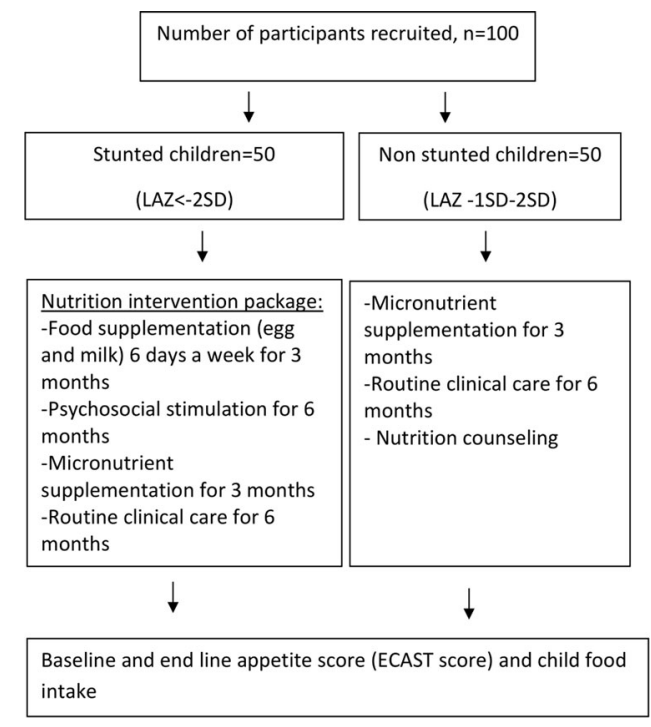

Fig. 1 Study design. We recruited 50 stunted and 50 non-stunted children aged between 12-18 months whose length-for-age Z-score was less than -2 and morethan or equal to -2 respectively. The enrolled stunted children received an intervention package on site, which included food supplementation (FS), micronutrient supplementation (MNP), psychosocial stimulation (PS) and routine clinical care. The non-stunted children received routine clinical care, MNP, and nutritional counseling but no FS or PS. At the end of intervention baseline and end line appetite score and food intake were measured.

\section{Intervention package}

The enrolled stunted children received an intervention package on site, which included one egg and $150 \mathrm{ml}$ milk (FS), as well as micronutrient supplementation daily (micronutrient powder (MNP)), 6 days a week, for 3 months, PS and routine clinical care for 6 months [26, 27].

The non-stunted children received routine clinical care, MNP, and nutritional counseling but no FS or PS.

\section{Food supplementation (FS)}

The FS provided an additional 178 kilocalories, $11.1 \mathrm{~g}$ protein, and $11.5 \mathrm{~g}$ of fat to the daily diet of enrolled subjects. After enrollment, stunted participants received directly observed nutrition intervention for a maximum of 30 min, 6 days a week, for 3 months, at the community nutrition center (CNC) established on site in Mirpur. Nonstunted children received one egg and $150 \mathrm{ml}$ milk at the $\mathrm{CNC}$ under direct supervision of trained research assistants once per month for 3 months, to systematically evaluate food intake. On the day of enrollment, the caregivers of all stunted children were provided a demonstration of responsive feeding practices (recognition of the child's cues of hunger and appetite and counseling regarding the need to encourage the child to self-feed and praise the child for his/ her feeding cues). Mothers/caregivers were discouraged from force feeding their children or administering physical punishment/verbal abuse while feeding. They were also advised not to distract the child while feeding at home (e.g., watching television) and were encouraged to attempt repeated feeding. The mother was requested to bring her child to the designated nutrition center daily for the nutrition intervention to avoid food sharing among family members. Freshly boiled egg and milk were provided every day to each participant. Provided food, intake, and leftover were measured using a structured questionnaire under direct supervision of trained research assistants to make sure that participants were having the controlled diets only. They were also provided with phone numbers of field staff to ensure compliances (such as any information based on study or medical assistance) whenever they required.

\section{Psychosocial stimulation (PS)}

The PS received by stunted children was comprised of parental counseling provided by trained health workers referred to as play leaders [26, 27]. The play leaders were trained by the study investigators to provide play sessions. The sessions were conducted at the CNC, weekly for 1 st month, fortnightly for the 2nd and 3rd months and then monthly for the next 3 months. The total number of visits was 11 over a period of 6 months.

Play sessions The play sessions were comprised of a half an hour play session using culturally appropriate homemade toys with child and mother/caregiver on a one-to-one interaction. Examples of some of the toys are plastic rattles using plastic bottles, drums using discarded tins, balls and dolls made of used clothes, stacking bottles using plastic bottles cut into halves, wooden blocks using discarded wood pieces, push along and pull along toys using discarded tins of bigger size with a string or rope. Mothers/ caregivers were fully involved in all the activities and were encouraged to give stimulation to their children by themselves at their home at least three to four times a day. A check-list was used during each visit in an attempt to ensure active participation of the mother/caregiver in providing PS to the child at home.

Parental counseling Parental counseling included a half an hour session, with every mother/caregiver and child focused on improving child-rearing practices and enhancing mother-child interaction for optimal child growth and development. During the sessions, the play leader emphasized the importance of play with the child, chatting, singing song/rhymes, showing love, and giving praise to the child. The play leader also demonstrated how to incorporate play into routine activities like feeding, bathing, sleeping, and getting dressed. The mothers/caregivers 
were highly discouraged from using physical punishment or verbal abuse to control and discipline the child. The meetings were conducted in a participatory design and mothers/caregivers were encouraged to share their views and offer their suggestions.

\section{Routine clinical care}

During each follow-up visit at the $\mathrm{CNC}$, all children received routine medical care that included: physical examination, MNP (1 gm of MNP contains $42.90 \mathrm{mg}$ of vitamins, $0.150 \mathrm{mg}$ of folic acid, $10 \mathrm{mg}$ of elemental iron, $4.10 \mathrm{mg}$ of zinc, and $0.56,0.017,0.09 \mathrm{mg}$ of copper, selenium, and iodine), growth monitoring, treatment of intercurrent illnesses, health and nutrition education (counseling on infant and young child feeding practices, personal hygiene, hand washing), immunizations under Expanded Programme of Immunization schedule and de-worming (albendazole, $200 \mathrm{mg}$ single dose) if not given in the last 6 months. A physician was assigned to carry out routine clinical examination of the children, provide treatment accordingly and refer children to the study hospital (icddr,b) or other nearby hospitals for further management, if required. Health education and growth monitoring were also provided by trained health workers.

\section{Data collection}

After obtaining written informed consent, on enrollment, trained field research assistants collected anthropometric data and interviewed mothers/caregivers at home using a structured questionnaire, which included information on socio-demography (housing, sanitation, parental education, family income, and wealth) and assessed appetite score (ECAST score).

\section{Appetite score}

The children's appetite status was assessed by trained field staff, on enrollment and monthly for 6 months at CNC using an interview-based tool, the "Early Childhood Appetite and Satiety Tool (ECAST)." A description of the development and validation of this tool has been published previously [28]. The questionnaire was administered to mothers contained 27 items (detailed in Table 1) focused on "signs and cues of appetite" (5 items), "food consumption" (6 items), "food responsiveness" (4 items), "lethargy" (6 items), "emotion and preference" (6 items). The responses were coded as: never equals 1 , sometimes equals 2 , and often equals 3 . The total ECAST scores were obtained by summing up the responses and higher scores indicate good appetite [28].

\section{Anthropometry}

Anthropometry (weight and length) measurements were taken monthly for 6 months by trained field staff. Body weight was measured using Seca or Tanita scales (Seca 210, Seca Asia Pacific, 50470 Kuala Lumpur), which have an accuracy of $10 \mathrm{~g}$. Length was measured using a stadiometer length board (Seca 217, Secca,13601 Benson Avenue, CA 91710 Chino, USA) with $1 \mathrm{~mm}$ accuracy. Anthropometric measurements were taken routinely at a fixed time, preferably morning with minimal clothing and without shoes.

\section{Food intake assessment}

The stunted children were given $30 \mathrm{~min}$ to consume the meal (an egg and $150 \mathrm{ml}$ of milk). The control children were given the same food once a month for 3 months to assess their food intake. Both the duration and mass of food consumption were recorded digital cooking scales (TANITA analog cooking scale 1439, Tokyo, Japan) by trained research assistants. Weight of the leftover food was also recorded.

\section{Results}

A total of 100 children were enrolled (50 stunted and 50 non-stunted) into the study, and 77 children (41 stunted and 36 non-stunted) completed the 6 months follow-up. Demographic and baseline data are presented in Table 2. At enrollment, stunted children had a median age of 14 months and a median LAZ of -2.44 , and non-stunted children had a median age and LAZ of 15 months and -1.19 , respectively. In both groups, mothers were the primary caregivers, with a median age of 25 years.

\section{Appetite score}

Measurements of appetite score are presented in Table 3 as "on enrollment," "at the end of the 3 months," and "at the end of the 6 months." The mean appetite score was 50 in stunted children at enrollment, and rose to 60 after 6 months of intervention (Table 2) and increases gradually (Supplementary Table 1). The ten-point difference represents a significant increase from baseline. The mean appetite score was 51 in non-stunted children at enrollment, and rose to 56 over the same 6-month period (Fig. 2 and Supplementary Fig. 1).

\section{Food consumption}

We provided one egg (average weight is maximum $50 \mathrm{~g}$ ) and $150 \mathrm{~mL}$ of milk daily for 90 days to stunted children, 
Table 1 Early Childhood Appetite and Satiety Tool (ECAST)-27 items.

\begin{tabular}{|c|c|c|c|}
\hline Q & Factor & Item & Code \\
\hline & \multirow{6}{*}{$\mathrm{SC}$} & In the last $24 \mathrm{~h} . .$. & \multirow{6}{*}{$\begin{array}{l}1=\text { Never } \\
2=\text { Sometimes } \\
3=\text { Often }\end{array}$} \\
\hline 1 & & Did your child point for food that she/he want to eat? & \\
\hline 2 & & Did your child cry or asked for food? & \\
\hline 3 & & Did your child tug your clothes to let you know that she/he want to eat? & \\
\hline 4 & & Did your child show any interest in eating food? & \\
\hline 5 & & Did your child let you know when she/he was hungry? & \\
\hline 6 & \multirow[t]{6}{*}{$\mathrm{CO}$} & Did your child eat more than a few spoons, pinches, or balls of food? & \multirow{2}{*}{$\begin{array}{l}1=\text { Never } \\
2=\text { Sometimes } \\
3=\text { Often }\end{array}$} \\
\hline 7 & & Did your child finish all the food that was offered? & \\
\hline 8 & & How was your child's food intake? & $\begin{array}{l}1=\text { Less } \\
\text { than usual } \\
2=\text { Usual } \\
3=\text { More } \\
\text { than usual }\end{array}$ \\
\hline 9 & & Did your child prefer breast milk more than usual food? ${ }^{\mathrm{a}}$ & \multirow{3}{*}{$\begin{array}{l}1=\text { Never } \\
2=\text { Sometimes } \\
3=\text { Often }\end{array}$} \\
\hline 10 & & Did your child eat on his/her normal schedule (e.g., every 2 or $3 \mathrm{~h}$ )...? & \\
\hline 11 & & Did your child get full before his/her meal is finished? & \\
\hline 12 & \multirow[t]{4}{*}{$\mathrm{RF}$} & $\begin{array}{l}\text { Did you have to use special activities (singing a song, nursery rhymes, } \\
\text { playing a game, showing a video) more than normal to help your child } \\
\text { eat? }\end{array}$ & \multirow[t]{4}{*}{$\begin{array}{l}1=\text { Never } \\
2=\text { Sometimes } \\
3=\text { Often }\end{array}$} \\
\hline 13 & & Did you have to spend more time than normal to feed your child? ${ }^{\mathrm{a}}$ & \\
\hline 14 & & $\begin{array}{l}\text { Did you have to force your child to eat because she/he does not eat what } \\
\text { you offered? }\end{array}$ & \\
\hline 15 & & $\begin{array}{l}\text { Did you have to offer foods in order to get your child to eat that you } \\
\text { thought were unhealthy? }\end{array}$ & \\
\hline 16 & \multirow[t]{6}{*}{ LE } & Did your child show enough interest to eat? & \multirow{6}{*}{$\begin{array}{l}1=\text { Never } \\
2=\text { Sometimes } \\
3=\text { Often }\end{array}$} \\
\hline 17 & & Did you have to offer only liquids/drinks to feed your child? ${ }^{\mathrm{a}}$ & \\
\hline 18 & & $\begin{array}{l}\text { Did any illnesses like diarrhea or fever keep your child away from eating } \\
\text { less than normal? }^{\mathrm{a}}\end{array}$ & \\
\hline 19 & & Did your child take more than $30 \mathrm{~min}$ to finish his/her meal? & \\
\hline 20 & & Did your child vomit after eating? ${ }^{\mathrm{a}}$ & \\
\hline 21 & & Did your child eat very quickly? & \\
\hline 22 & \multirow[t]{6}{*}{ EP } & $\begin{array}{l}\text { Did you need to present foods in an attractive way to get your child to } \\
\text { eat? }{ }^{\text {a }} \text { (ex: colorful food and plates, specific plate, present food in an } \\
\text { attractive way) }\end{array}$ & \multirow[t]{6}{*}{$\begin{array}{l}1=\text { Never } \\
2=\text { Sometimes } \\
3=\text { Often }\end{array}$} \\
\hline 23 & & Did you have to arrange special foods to get your child to eat? & \\
\hline 24 & & Was your child interested to eat? & \\
\hline 25 & & Did your child enjoy his/her meal when praised or encouraged? ${ }^{a}$ & \\
\hline 26 & & $\begin{array}{l}\text { Did your child want the same food even after different foods were } \\
\text { offered? }^{\mathrm{a}}\end{array}$ & \\
\hline 27 & & Did your child preferred to eat his/her favorite foods & \\
\hline
\end{tabular}

$S C$ sign and cues, $C O$ consumption, $E P$ emotional preference, $F R$ food responsiveness, $L E$ lethargy.

${ }^{a}$ Reverse coding for data analysis. and the same food was provided once in a month to measure appetite score and food intake for 3 months among non-stunted children. Children in both groups increased food consumption during the study. Stunted children consumed $40.3 \mathrm{~g} \mathrm{egg}$ at enrollment which increased significantly to $49.6 \mathrm{~g}$ at end line, and $83.8 \mathrm{ml}$ milk at baseline and $138.5 \mathrm{ml}$ milk at end line. Similarly, non-stunted children consumed 40.3 and $50.0 \mathrm{~g}$ egg, and 92 and $130 \mathrm{ml}$ milk at baseline and end line accordingly (Table 4 and Supplementary Table 2).

\section{Discussion}

The primary objective of the study was to see the changes in appetite status of stunted children after receiving nutritional 
intervention. Prior studies have assessed the use of an appetite score based on food consumption, whereas the present study measured appetite using a previously validated interview-based tool [28, 30]. The results of this study suggest that stunted children in Bangladesh receiving a nutrition intervention comprised of FS and PS had measurably increased appetite over a period of 6 months.

A number of studies have shown positive impact of nutrition interventions on nutritional status and child development in malnourished children [25-27]. A prior study of stunted children ages 9-24 months, divided into four groups receiving either FS or PS, both, or none, demonstrated a significant beneficial effect of FS and PS on child development through early adolescence [31].

Any food-based intervention must include nutritious, available and affordable food, and avoid social and cultural taboos [32]. Numerous studies have demonstrated significant increases in linear growth and reduced stunting with milk or eggs. Interestingly, all the studies that intervened with milk were limited to age groups between 6 and 17 years [33-36]. The present study provided both eggs and

Table 2 Baseline characteristics of stunted and non-stunted children.

\begin{tabular}{llll}
\hline Characteristics & $\begin{array}{l}\text { Stunted } n= \\
50(\%)\end{array}$ & $\begin{array}{l}\text { Non-stunted } \\
n=50(\%)\end{array}$ & $P$ value \\
\hline $\begin{array}{l}\text { Age of caregivers (years), } \\
\text { median (IQR) }\end{array}$ & $23(20,27)$ & $23(20,28)$ & 0.449 \\
$\begin{array}{l}\text { Type of caregivers: mother } \\
\text { Grade of schooling }\end{array}$ & $49(98)$ & $50(100)$ & 1.000 \\
$\begin{array}{l}\text { No education } \\
\text { Primary }\end{array}$ & $10(20)$ & $14(28)$ & 0.626 \\
$\begin{array}{l}\text { Secondary and above } \\
\begin{array}{l}\text { Occupation } \\
\text { House wife }\end{array}\end{array}$ & $20(40)$ & $19(38)$ & \\
$\begin{array}{l}\text { Working women } \\
\text { Age of child (months), }\end{array}$ & $14(13,18)$ & $15(12,16)$ & 0.667 \\
median (IQR) & $43(86)$ & $46(92)$ & 0.338 \\
$\begin{array}{l}\text { Length-for-age } z \text {-score, } \\
\text { mean } \pm \text { SD }\end{array}$ & $-2.44 \pm 0.27$ & $-1.19 \pm 0.40$ & $<0.001$ \\
$\begin{array}{l}\text { Sex of the child: female } \\
\text { H/o exclusive breast }\end{array}$ & $30(60)$ & $27(54)$ & 0.545 \\
$\begin{array}{l}\text { feeding } \\
\text { Appropriate onset of CF }\end{array}$ & $30(60)$ & $36(72)$ & 0.205 \\
\hline
\end{tabular}

milk, 6 days a week for 90 days, to children in a younger age group, where stunting is more prevalent [37]. The duration of the FS in this study was similar to that reported in other studies of nutritional intervention in Bangladesh (3 months) [27, 38].

Micronutrient supplementation was included in the nutrition intervention package in this study. The increased appetite score among stunted children could suggest that the lack of appetite at enrollment was a result of specific micronutrient deficiencies in this population. This result is supported by a prior study conducted in Southern Benin, where micronutrient supplementation improved appetite and growth among young children [12].

Positive parent-child communication and activities that encourage creative play and social connection facilitate the development of child's appetite [39]. A number of studies have shown that children under 3-4 years of age eat primarily in response to appetite or hunger cues, whereas older children's eating habits are influenced by a variety of environmental and social factors [40, 41]. We provided parenting intervention through PS sessions, which may have helped to increase interest in food intake including understanding of appetite or hunger cues. We calculated appetite scores monthly to determine whether there were subsequent improvements in scores.

We provided FS for 3 months and PS for 6 months to the stunted children. Interestingly, the baseline appetite score and food intake were almost the same in both stunted and non-stunted children in this study. Other studies have also observed similar appetite and food intake patterns in stunted and non-stunted children [31]. At the end of 6 months, stunted children had increased appetite scores. Interestingly, we also found increased food intake over time in the nonstunted children without any nutrition intervention. This may reflect temporal or natural changes in appetite with age or could be a result of micronutrient supplementation. However, micronutrient supplementation alone did not increase appetite among young Beninese children [42]. In our study, we provided food at the community nutrition clinic and stunted children consumed the provided food under direct supervision of field research assistants assuring that no food was shared with other family members.

This study provided a combined intervention package of animal-based foods, micronutrient supplementation, PS, and routine clinical care to stunted children. The study
Table 3 ECAST score among stunted and non-stunted group on enrollment, at 3 and 6 months.

\begin{tabular}{llllllll}
\hline & \multicolumn{2}{l}{ Stunted } & & & \multicolumn{2}{l}{ Non-stunted } \\
\cline { 2 - 3 } & Mean & Upper limit & Lower limit & & Mean & Upper limit & Lower limit \\
\hline On enrollment & 49.8 & 48.6 & 51.1 & & 51.5 & 49.9 & 53.2 \\
At 3 months & 56.7 & 54.8 & 58.7 & & 54.0 & 52.2 & 55.8 \\
At 6 months & 60.3 & 58.2 & 62.4 & & 56.3 & 54.3 & 58.4 \\
\hline
\end{tabular}


Table 4 Changes in food consumption in baseline and end line in stunted children.

\begin{tabular}{|c|c|c|c|c|c|c|}
\hline \multirow[t]{2}{*}{ Type of food intake } & \multicolumn{3}{|l|}{ Stunted } & \multicolumn{3}{|l|}{ Non-stunted } \\
\hline & Baseline $(n=50)$ & End line $(n=41)$ & $P$ value ${ }^{a}$ & Baseline $(n=50)$ & End line $(n=36)$ & $P$ value $^{\mathrm{a}}$ \\
\hline Consumption of egg $(g)($ mean \pm SD $)$ & $40.36 \pm 16.29$ & $49.63 \pm 13.87$ & 0.003 & $40.35 \pm 19.11$ & $50.02 \pm 12.75$ & 0.007 \\
\hline Consumption of milk $(\mathrm{ml})($ mean $\pm \mathrm{SD})$ & $83.88 \pm 43.75$ & $138.58 \pm 23.94$ & 0.000 & $91.98 \pm 46.42$ & $129.52 \pm 32.99$ & 0.000 \\
\hline
\end{tabular}

${ }^{a}$ Difference shown between baseline and end line by paired $t$-test.

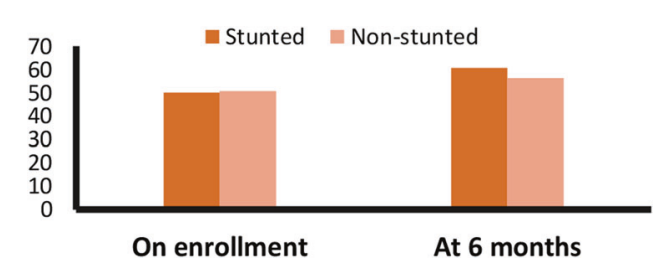

Fig. 2 Appetite status of the children on enrollment and after 6 months of intervention. We provided food supplementation 6 days a week for 3 months and measured appetite score monthly. The mean appetite score was 50 in stunted children at enrollment, and increased to 60 after 6 months of intervention whereas the mean appetite score was 51 in non-stunted children at enrollment, and rose to 56 over the same 6-month period.

provides an initial assessment of the impact of FS and PS on appetite status using an interview-based tool (ECAST). In this study, stunted children who received CNC-delivered nutrition supplementation and PS exhibited increased appetite over time. Future trials to determine whether such improvements in appetite are also associated with improved nutritional recovery are needed.

\section{Strengths and limitations}

This study had several important strengths. First, the study was conducted in a population where stunting is highly prevalent and interventions to reduce the adverse consequences of stunting are desperately needed. The study used a validated tool to measure appetite and data were collected by well trained staff in a research setting. However, the study also had several limitations. First, the inclusion of a group of non-stunted children was useful as a reference but as these children were not recruited in the same manner and did not receive the same intervention, they cannot be considered a true control group. In addition, the lack of a control group of individuals who did not receive the same intervention makes it impossible to attribute the change in appetite score to the intervention. Future trials will be needed to confirm the effect of such interventions on appetite and subsequent growth.

Acknowledgements icddr,b acknowledges with gratitude the commitment of Bill and Melinda Gates Foundation (BMGF) to its research efforts. icddr,b is also grateful to the Governments of Bangladesh,
Canada, Sweden, and the UK for providing core/unrestricted support. This study was registered on clinicaltrials.gov (Registration Number NCT02839148).

Author contributions NNN is the co-investigator of the project and responsible for development of concept, data collection and analysis, and reporting of the study results. MM and MH have contributed to the study design. JLW has contribution to the study design and provided his expert opinion, and MA has provided epidemiologic advice, opinion, and ideas during the study period. BN conceptualized the idea and was responsible for overall supervision of the project, development of ECAST, assisted in data analysis provided her valuable inputs from time to time, and edited draft. TA has contributed to the study design, development of concept, data analysis, and reviewed the draft. All authors read, reviewed, and approved the final paper.

Funding This project was funded by Bill and Melinda Gates Foundation.

\section{Compliance with ethical standards}

Conflict of interest The authors declare no competing interests.

Ethical approval Ethical approval was obtained from the icddr,b's Institutional Review Board (PR 16005).

Informed consent Before enrollment into the community-based trial, informed written consent was taken from the legal guardian of the participants.

Publisher's note Springer Nature remains neutral with regard to jurisdictional claims in published maps and institutional affiliations.

Open Access This article is licensed under a Creative Commons Attribution 4.0 International License, which permits use, sharing, adaptation, distribution and reproduction in any medium or format, as long as you give appropriate credit to the original author(s) and the source, provide a link to the Creative Commons license, and indicate if changes were made. The images or other third party material in this article are included in the article's Creative Commons license, unless indicated otherwise in a credit line to the material. If material is not included in the article's Creative Commons license and your intended use is not permitted by statutory regulation or exceeds the permitted use, you will need to obtain permission directly from the copyright holder. To view a copy of this license, visit http://creativecommons. org/licenses/by/4.0/.

\section{References}

1. Black RE, Allen LH, Bhutta ZA, Caulfield LE, De Onis M, Ezzati $\mathrm{M}$, et al. Maternal and child undernutrition: global and regional exposures and health consequences. Lancet. 2008;371:243-60. 
2. Dewey KG, Begum K. Long-term consequences of stunting in early life. Matern Child Nutr. 2011;7:5-18.

3. Grantham-McGregor S, Cheung YB, Cueto S, Glewwe P, Richter L, Strupp B, et al. Developmental potential in the first 5 years for children in developing countries. Lancet. 2007;369:60-70.

4. UNICEF W. Joint child malnutrition estimates: levels and trends. New York, NY: UNICEF; 2017.

5. De Onis M, Blössner M, Borghi E. Prevalence and trends of stunting among pre-school children, 1990-2020. Public Health Nutr. 2012;15:142-8.

6. Bhutta ZA, Ahmed T, Black RE, Cousens S, Dewey K, Giugliani $\mathrm{E}$, et al. What works? Interventions for maternal and child undernutrition and survival. Lancet. 2008;371:417-40.

7. Talukder A. Factors associated with malnutrition among underfive children: illustration using Bangladesh demographic and health survey, 2014 data. Children. 2017;4:88

8. Paxson C, Schady N. Cognitive development among young children in Ecuador the roles of wealth, health, and parenting. J Hum Resour. 2007;42:49-84.

9. Brown KH, Peerson JM, Lopez de Romana G, de Kanashiro HC, Black RE. Validity and epidemiology of reported poor appetite among Peruvian infants from a low-income, periurban community. Am J Clin Nutr. 1995;61:26-32.

10. Korpe PS, Petri WA Jr. Environmental enteropathy: critical implications of a poorly understood condition. Trends Mol Med. 2012;18:328-36.

11. Ahmed T, Haque R, Shamsir Ahmed AM, Petri WA Jr, Cravioto A. Use of metagenomics to understand the genetic basis of malnutrition. Nutr Rev. 2009;67:S201-6.

12. Dossa RA, Ategbo EA, van Raaij JM, de Graaf C, Hautvast JG. An appropriate tool for appetite testing and evaluation in young children in Benin. Appetite. 2002;38:99-109.

13. Allen H, Gillespie SA. What works? A review of the efficacy and effectiveness of nutrition interventions. Asian Development Bank; 10 Dec 2001.

14. Bentley ME, Black MM, Hurtado E. Child-feeding and appetite: what can programmes do. Food Nutr Bull. 1995;16:340-9.

15. Waterlow J. Summary of causes and mechanisms of linear growth retardation. Eur J Clin Nutr. 1994;48:210.

16. Hamadani JD, Huda SN, Khatun F, Grantham-McGregor SM. Psychosocial stimulation improves the development of undernourished children in rural Bangladesh. $J$ Nutr. 2006;136:2645-52.

17. Garcia S, Kaiser L, Dewey K. The relationship of eating frequency and caloric density to energy intake among rural Mexican preschool children. Eur J Clin Nutr. 1990;44:381-7.

18. Garcia S, Kaiser L, Dewey K. Self-regulation of food intake among rural Mexican preschool children. Eur J Clin Nutr. 1990;44:371-80.

19. Dong C, Ge P, Ren X, Wang J, Fan H, Yan X, et al. Prospective study on the effectiveness of complementary food supplements on improving status of elder infants and young children in the areas affected by Wenchuan earthquake. PLoS ONE. 2013;8:e72711.

20. Rah JH, de Pee S, Halati S, Parveen M, Mehjabeen SS, Steiger G, et al. Provision of micronutrient powder in response to the Cyclone Sidr emergency in Bangladesh: cross-sectional assessment at the end of the intervention. Food Nutr Bull. 2011;32:277-85.

21. Jayatissa R, Bekele A, Kethiswaran A, De Silva A. Communitybased management of severe and moderate acute malnutrition during emergencies in Sri Lanka: challenges of implementation. Food Nutr Bull. 2012;33:251-60.

22. Ashworth A. Efficacy and effectiveness of community-based treatment of severe malnutrition. Food Nutr Bull. 2006;27: S24-48.
23. Sadler K, Myatt M, Feleke T, Collins S. A comparison of the programme coverage of two therapeutic feeding interventions implemented in neighbouring districts of Malawi. Public Health Nutr. 2007;10:907-13.

24. Sadler K, Puett C, Mothabbir G, Myatt M Community case management of severe acute malnutrition in southern Bangladesh. Boston: Tufts University. 2011.

25. Daniel AI, Bandsma RH, Lytvyn L, Voskuijl WP, Potani I, Van Den Heuvel M Psychosocial stimulation interventions for children with severe acute malnutrition: a systematic review. Journal of global health. 2017;7.

26. Nahar B, Hamadani JD, Ahmed T, Tofail F, Rahman A, Huda S, et al. Effects of psychosocial stimulation on growth and development of severely malnourished children in a nutrition unit in Bangladesh. Eur J Clin Nutr 2009;63:725.

27. Nahar B, Hossain M, Hamadani J, Ahmed T, Huda S, GranthamMcGregor S, et al. Effects of a community-based approach of food and psychosocial stimulation on growth and development of severely malnourished children in Bangladesh: a randomised trial. Eur J Clin Nutr. 2012;66:701.

28. Nahar B, Hossain M, Ickes SB, Naila NN, Mahfuz M, Hossain D. et al. Development and validation of a tool to assess appetite of children in low income settings. Appetite. 2019;134:182-92.

29. Hanks LJ, Gutiérrez OM, Bamman MM, Ashraf A, McCormick KL, Casazza K. Circulating levels of fibroblast growth factor-21 increase with age independently of body composition indices among healthy individuals. J Clin Transl Endocrinol.2015;2:77-82.

30. Naila N, Nahar B, Lazarus M, Ritter G, Hossain M, Mahfuz M, et al. "Those who care much, understand much." Maternal perceptions of children's appetite: perspectives from urban and rural caregivers of diverse parenting experience in Bangladesh. Matern Child Nutr. 2018;14:e12473.

31. Walker SP, Powell CA, Grantham-McGregor SM. Dietary intakes and activity levels of stunted and non-stunted children in Kingston, Jamaica. Part 1. Dietary intakes. Eur J Clin Nutr. 1990;44:527-34.

32. Naser I. Role of protein-based food (PBF) in combating undernutrition; milk and eggs as an example. J Nutr Disord Ther. 2016;6:21610509.1000184.

33. Berkey CS, Colditz GA, Rockett HR, Frazier AL, Willett WC. Dairy consumption and female height growth: prospective cohort study. Cancer Epidemiol Biomarkers Prev. 2009;18:1881-7.

34. Wiley AS. Does milk make children grow? Relationships between milk consumption and height in NHANES 1999-2002. Am J Hum Biol. 2005; 17:425-41.

35. Xueqin D, Zhu K, Trube A, Zhang Q, Ma G, Hu X, et al. Schoolmilk intervention trial enhances growth and bone mineral accretion in Chinese girls aged 10-12 years in Beijing. Br J Nutr. 2004;92:159-68.

36. Kabir I, Rahman MM, Haider R, Mazumder RN, Khaled MA, Mahalanabis D. Increased height gain of children fed a highprotein diet during convalescence from shigellosis: a six-month follow-up study. J Nutr. 1998;128:1688-91.

37. Niport M. Bangladesh demographic and health survey BDHS 2014: key indicators. Dhaka and Calverton, MD: National Institute of Population Research and Training (NIPORT), Mitra and Associates, and ICF International; 2014.

38. Waber DP, Vuori-Christiansen L, Ortiz N, Clement JR, Christiansen NE, Mora JO, et al. Nutritional supplementation, maternal education, and cognitive development of infants at risk of malnutrition. Am J Clin Nutr. 1981;34:807-13.

39. Powell F, Farrow C, Haycraft E. Appetite regulation in early childhood: the impact of parenting behaviours and child temperament. In: Mitchell SR, editor. Appetite: regulation, role in disease and control. Nova Publishers; 2011. p. 1-28. 
40. Birch LL, Engell D, Rolls BJ. Serving portion size influences 5year-old but not 3-year-old children's food intakes. J Am Diet Assoc. 2000;100:232-34.

41. Rodenburg G, Kremers SP, Oenema A, van de Mheen D. Associations of children's appetitive traits with weight and dietary behaviours in the context of general parenting. PLoS One. 2012;7: e50642.

42. Dossa R, Ategbo E, van Raaij J, De Graaf C, Hautvast J. Effects of multivitamin-multimineral supplementation on appetite of stunted young Beninese children. Appetite. 2002;39:111-7. 